\title{
RESPOSTAS FISIOLÓGICAS DE GENÓTIPOS \\ DE AMENDOIM À DEFICIÊNCIA HÍDRICA
}

PHYSIOLOGICAL RESPONSES OF PEANUT GENOTYPES TO WATER DEFICIT

\section{Willians César Carrega}

Pós-doutorando na Universidade Estadual Paulista "Júlio de Mesquita Filho" (UNESP)-Jaboticabal (SP), Brasil.

\section{Juciléia Irian dos Santos}

Engenheira Agrônoma na Secretaria de Agricultura e Abastecimento do Estado deSão Paulo-Guapiara (SP), Brasil.

\section{Anne Elise Cesarin}

Docente na Universidade de Franca (UNIFRAN) - Franca (SP), Brasil.

\section{Gianmarco José}

Tironi Gallardo (D)

Gerente Técnico de Vendas na Nutrien Ag Solutions - Santiago, Chile.

\section{Allan Lopes Bacha iD}

Doutorando na Universidade Estadual Paulista "Júlio de Mesquita Filho" (UNESP)-Jaboticabal (SP), Brasil.

\section{Ignácio José de Godoy (iD)}

Pesquisador Científico no Instituto Agronômico de Campinas (IAC) Campinas (SP), Brasil.

\section{Pedro Luis da Costa Aguiar Alves}

Docente na Universidade Estadual Paulista "Júlio de Mesquita Filho" (UNESP) - Jaboticabal (SP), Brasil.

\section{Endereço para correspondência: Willians César Carrega - Via de Acesso Prof. Paulo Donato Castellane, $\mathrm{s} / \mathrm{n}$ - Bairro Rural - CEP 14884-900 - Jaboticabal (SP), Brasil - E-mail: willianscesar@hotmail.com}

Recebido em: 30/10/2019

Aceito em: 17/12/2019

\section{RESUMO}

Entre os fatores ambientais, a deficiência hídrica tem efeito em diversos processos morfológicos e fisiológicos das plantas, podendo afetar o crescimento e o desenvolvimento das culturas, refletindo na produtividade. Diante disso, objetivou-se avaliar as características fisiológicas de genótipos de amendoim submetidos à deficiência hídrica. Realizou-se um experimento em blocos inteiramente casualizados, com os tratamentos dispostos em esquema fatorial $12 \times 2$, tendo como tratamentos 12 genótipos e duas condições hídricas, em cinco repetições. Para avaliar o efeito do estresse, aos 25 dias após a emergência (DAE), as plantas de amendoim permaneceram sob deficiência hídrica por quatro dias, enquanto as testemunhas foram mantidas a $70 \%$ da capacidade de campo. Aos $29 \mathrm{DAE}$, foram realizadas as avaliações de fotossíntese, transpiração, teor relativo de água, teor de cera epicuticular e massa seca das plantas. A taxa fotossintética foi menor para todos os genótipos sob deficiência hídrica, exceto para a linhagem 870, que demonstrou maior tolerância à seca. Para a transpiração, as cultivares Runner IAC 886, IAC OL3, IAC OL4 e as linhagens 573, 599, 870 não foram afetados pela deficiência hídrica. Entre os genótipos, há variação na quantidade de ceras epicuticulares sob condições hídricas. Com relação ao comportamento anatomofisiológico dos genótipos, concluiu-se que as linhagens 573 e 870 são altamente tolerantes à deficiência hídrica, as cultivares IAC OL3, IAC OL4, Runner IAC 886 e as linhagens 599 e 967 são moderadamente tolerantes e IAC 503, IAC 505 e IAC Tatu-ST e as linhagens 322 e 506 são mais sensíveis ao estresse hídrico durante a fase de florescimento.

Palavras-chave: água; Arachis hypogaea L.; cera epicuticular; fotossíntese; multivariada; transpiração.

\section{ABSTRACT}

Among the environmental factors, water deficit affects several morphological and physiological processes in plants, which may affect crops' growth and development, reflecting on the yield. Thus, the aim of this research was to evaluate the physiological responses of peanut genotypes submitted to water deficit. The experimental design was a completely randomized block with treatments in a $12 \times 2$ factorial arrangement, with twelve genotypes and two hydric conditions, with 5 replications. To evaluate the effect of stress, at 25 days after emergence (DAE) peanut plants were kept under water deficiency for four days, while the controls were kept at $70 \%$ of field capacity. At $29 \mathrm{DAE}$, photosynthesis, transpiration rate, relative water and epicuticular wax content were evaluated. The photosynthetic rate was lower for all water deficit genotypes, except for the 870 strain, which showed higher drought tolerance. Water deficit did not affect the transpiration rate of Runner IAC 886, IAC OL3, IAC OL4 cultivars and 573, 599,870 breeding lines. Among the genotypes, there is variation in the amount of the epicuticular waxes under water-deficit conditions. In relation 
to anatomo-physiological aspects from the genotypes, it was concluded that lines 573 and 870 are highly tolerant to water deficiency; cultivars IAC OL3, IAC OL4, Runner IAC 886, and 599 and 967 lines are moderately tolerant, and IAC 503, IAC 505 and IAC Tatu-ST, and lines 322 and 506 are more sensitive to water stress during phase of flowering.

Keywords: water; Arachis hypogaea L.; epicuticular wax; photosynthesis; multivariate; transpiration.

\section{INTRODUÇÃO}

O amendoim (Arachis hypogaea L.) é uma leguminosa da família Fabaceae que possui elevada importância em âmbito mundial, sendo a quarta maior cultura oleaginosa. Com produção estimada em 45 milhões de toneladas (USDA, 2019), é utilizado principalmente na extração de óleo comestivel, na ração animal e na indústria de confeitaria (RODRIGUES et al., 2016).

Atualmente o cenário agrícola tem passado por alterações ambientais sobretudo em razão das mudanças climáticas. De acordo com dados divulgados pela Administração Nacional da Aeronáutica e Espaço (NASA, 2019), tem ocorrido aumento severo na temperatura global, que provoca anos atípicos, ou seja, épocas com chuvas normais (circunstância ideal para o cultivo), épocas com chuvas muito intensas e épocas com secas severas. Essas mudanças climáticas afetam os cultivos agrícolas, prejudicando o desenvolvimento das plantas e reduzindo a produtividade das culturas, o que gera instabilidade econômica no setor agrícola.

A deficiência hídrica em qualquer fase do ciclo, dependendo da sua intensidade, pode levar as plantas a desenvolver mecanismos de adaptação à seca, que poderão ser de natureza morfológica, fisiológica, anatômica e bioquímica, interferindo negativamente no crescimento e na produtividade do amendoim. Segundo Songsri et al. (2008), em áreas onde a seca é recorrente, as perdas no rendimento do amendoim podem variar entre 22 e $53 \%$ e aumentar a contaminação por aflatoxinas de 2 a 17\% (GIRDTHAl et al., 2010). Estas perdas decorrentes da seca são anualmente estimadas em US\$ 520 milhões (KAMBIRANDA et al., 2011). Diante disso, a seleção de cultivares tolerantes à seca é uma alternativa para manter o rendimento do amendoim sob deficiência hídrica (POLANIA et al., 2017). De acordo com Shen et al. (2015), muitas pesquisas têm reportado a tolerância de amendoim à seca. Portanto, muitos programas de melhoramento de amendoim estão buscando aperfeiçoar a produtividade de genótipos sob deficiência hídrica (THANGTHONG et al., 2018).
O amendoinzeiro é uma oleaginosa conhecida por apresentar tolerância ao estresse hídrico, principalmente pela sua habilidade em viver em ambientes com baixa disponibilidade de água (PEREIRA et al., 2012; NOGUEIRA; SANTOS, 2000). Essa habilidade é um mecanismo de adaptação que as plantas apresentam para assegurar a sobrevivência da espécie. Sob deficiência hídrica, podem ocorrer vários transtornos fisiológicos e bioquímicos nas plantas, causados pelas flutuações no ambiente abiótico (TAIZ et al., 2017). Carrega (2017) afirma que há uma série de processos capazes de contribuir para minimizar a perda de água pelas plantas, como: fechamento estomático, ajustamento da parece celular, ajustamento osmótico, menor produção de folhas, redução da área foliar, aumento na densidade e profundidade de raízes e espessamento da cutícula.

Entre os mecanismos adaptativos, a cutícula (constituída de cutina e ceras) desempenha papel fundamental na fisiologia das plantas, sendo responsável por regular a perda de água, íons e nutrientes entre as células epidérmicas e a atmosfera (BUSCHHAUS; HERZ; JETTER, 2007; GUHLING et al., 2005). As propriedades físicas e químicas da cera cuticular determinam funções vitais para as plantas (BUSCHHAUS; HERZ; JETTER, 2007), como fotossíntese e transpiração.

A compreensão dos mecanismos utilizados pelas plantas para tolerar a deficiência hídrica é de suma importância para a tomada de decisão durante a implantação de um sistema de cultivo. Como a cultura do amendoim apresenta determinada tolerância ao estresse hídrico, é necessário saber quais mecanismos estão envolvidos no processo adaptativo dessa planta, visando selecionar genótipos com maior tolerância à seca. De posse dessas informações, há a possibilidade de cultivá-la em regiões com menor disponibilidade hídrica, bem como fornecer subsídios para o aumento da sua produção nacional. Diante disso, o objetivo deste trabalho foi avaliar o comportamento fisiológico de genótipos de amendoim submetidos à deficiência hídrica. 


\section{MATERIAIS E MÉTODOS}

O experimento foi conduzido em delineamento em blocos inteiramente casualizados, com os tratamentos dispostos em esquema fatorial $12 \times 2$, com cinco repetições. Constituíram os tratamentos 12 genótipos de amendoim (cultivares: IAC 503, IAC 505, Runner IAC 886, IAC OL3, IAC OL4 e IAC Tatu-ST; e linhagens: 322, $506,573,599,870$ e 967$)$, submetidos a duas condições hídricas (com e sem deficiência hídrica).

A seleção dessas cultivares para o presente estudo foi baseada na ausência de informações sobre as respostas ao déficit hídrico. No programa de melhoramento de amendoim, essa linha de pesquisa tem sido pouco explorada. Por isso, para este estudo, foram selecionadas as cultivares comerciais mais representativas na principal região produtora de amendoim no país. Além disso, selecionaram-se também linhagens que ainda estão em fase de melhoramento, mas que têm potencial para serem lançadas como cultivares no futuro.

A semeadura foi realizada em caixas plásticas com capacidade volumétrica para $2 \mathrm{~L}$, preenchidas com substrato composto de mistura de solo (latossolo vermelho escuro) e areia (2:1 v/v). Em cada caixa, foram depositadas 15 sementes, previamente tratadas com inseticida tiametoxam ( $200 \mathrm{~mL}$ do produto comercial - p.c./100 kg de sementes) e fungicida carboxina + tiram (200 SC - $350 \mathrm{~mL}$ do p.c./100 kg de sementes). Após a emergência das plantas, realizou-se o desbaste, deixando-se duas plantas por caixa.

Aos 25 dias após a emergência (DAE), as plantas foram submetidas aos tratamentos (com e sem deficiência hídrica) por quatro dias. Nesse período, as plantas sob deficiência hídrica ficaram em estufa plástica de polietileno transparente, sendo esta aberta no dia de ausência de chuvas, enquanto no tratamento controle (sem deficiência hídrica) as plantas foram mantidas a $70 \%$ da capacidade de campo. Para ambas as situações, o monitoramento da umidade do solo foi realizado por meio de sensores (HidroFarm, Falker, modelo HFM 2010/ HFM 2030) colocados nos substratos. Os dados da umidade dos substratos no decorrer do período de estresse hídrico estão expressos na Tabela 1.

Após o término do período de deficiência hídrica (29 DAE), procederam-se às avaliações da fotossíntese e transpiração em quatro folíolos (IRGA - LICOR, modelo LI-6400), sendo as leituras realizadas nas condições ambientes vigentes (temperatura do ar 25으, umidade relativa do ar $30 \%$ e concentração de $\mathrm{CO}_{2}$ de $400 \mu \mathrm{mol} \mathrm{m} \mathrm{m}^{-2} \mathrm{~s}^{-1}$, utilizando intensidade de luz equivalente a $1.500 \mu \mathrm{mol} \mathrm{m} \mathrm{m}^{-2} \mathrm{~s}^{-1}$ ). Para a fotossíntese e a transpiração, os resultados foram expressos em $\mu \mathrm{mol}$ $\mathrm{CO}_{2} \mathrm{~m}^{-2} \mathrm{~s}^{-1}$ e mmol $\mathrm{H}_{2} 0 \mathrm{~m}^{-2} \mathrm{~s}^{-1}$, respectivamente, de acordo com Evans e Santiago (2014), e, para os cálculos, determinaram-se as áreas foliares totais dos quatro folíolos. Na sequência, foi determinado o teor relativo de água (TRA) nas folhas dos amendoinzeiros (terceira folha da haste principal), segundo procedimento descrito por Weatherley (1950).

Após as avaliações fisiológicas, fez-se a quantificação das ceras epicuticulares de 30 folíolos jovens, coletados na parte superior da haste principal de cada genótipo, seguindo metodologia descrita por Silva Fernandes, Baker e Martin (1964), e os valores foram expressos em $\mu \mathrm{g} \mathrm{cm}{ }^{-2}$.

Ao término do período experimental, aos $29 \mathrm{DAE}$, foi determinada a massa seca da parte aérea das plantas após secagem em estufa de circulação forçada de ar, a $70^{\circ} \mathrm{C}$, até atingir massa constante.

Os resultados obtidos foram submetidos à análise de variância pelo teste $\mathrm{F}$ e as médias comparadas pelo teste de Tukey a $5 \%$ de probabilidade, utilizando o

Tabela 1 - Umidade média dos substratos com genótipos de amendoim sob duas condições hídricas, durante o período de imposição do estresse.

\begin{tabular}{|l|c|c|c|c|}
\multirow{2}{*}{ Tratamentos } & \multicolumn{4}{|c|}{ Umidade do substrato (\%) } \\
\cline { 2 - 5 } & 26 DAE & 27 DAE & 28 DAE & $19,07 \pm 0,18$ \\
\hline Sem estresse hídrico & $19,05 \pm 0,42$ & $18,47 \pm 0,30$ & $18,90 \pm 0,10$ & $19,13 \pm 0,96$ \\
\hline Com estresse hídrico & $14,17 \pm 0,87$ & $9,07 \pm 0,70$ & $7,43 \pm 0,72$ & 6,13 \\
\hline
\end{tabular}

DAE: dias após a emergência. 
software Agrostat (BARBOSA; MALDONADO JÚNIOR, 2015). Por meio das características avaliadas, realizou-se a análise de agrupamento pelo método Ward, por meio da distância euclidiana e da análise de componentes principais (ACP), com auxílio do software Statistica (2016).

\section{RESULTADOS}

Observaram-se diferenças significativas entre as condições hídricas e entre os genótipos e a interação entre as condições hídricas e os genótipos de amendoim para todos os parâmetros avaliados (Tabela 2).

Para facilitar a compreensão dos resultados, a análise fatorial foi separada nas Figuras 1 e 2, demonstrando as diferenças de cada genótipo com e sem deficiência hídrica. Na Tabela 3 está a comparação entre todos os genótipos sob deficiência hídrica e sob disponibilidade hídrica.

Para as cultivares IAC 503 (Figura 1A), IAC 505 (Figura 1B) e linhagem 967 (Figura 2F), verificou-se que as plantas sob menor disponibilidade hídrica apresentaram reduções no TRA, fotossíntese e transpiração, mas não demonstraram diferenças significativas entre os teores de cera epicuticular e massa seca da parte aérea.

IAC OL3 (Figura 1C), IAC OL4 (Figura 1D) e linhagem 599 (Figura 2D) sob estresse hídrico exibiram reduções na fotossíntese, no teor de cera e na massa seca da parte aérea, sem que houvesse redução significativa no TRA nem na transpiração.

Para a cultivar Runner IAC 886 (Figura 1E) e a linhagem 573 (Figura 2C), observou-se que a deficiência hídrica afetou apenas a atividade fotossintética, sem causar redução na massa seca da parte aérea das plantas. Para os demais parâmetros, TRA, transpiração, teor de cera epicuticular e massa seca da parte aérea, não foram constatadas diferenças significativas.
Quando as plantas da cultivar IAC Tatu-ST (Figura 1F) e da linhagem 322 (Figura 2A) estavam sob deficiência hídrica, notaram-se reduções para todos os parâmetros avaliados, exceto para a massa seca da parte aérea.

A linhagem 506 (Figura 2B) sob deficiência hídrica foi o único genótipo que apresentou diferença significativa para o teor de cera epicuticular, com maior teor quando comparada com o tratamento hidratado. Independentemente disso, as demais características (fotossíntese, transpiração e massa seca da parte aérea) foram afetadas de modo negativo pelo estresse causado pela menor disponibilidade hídrica.

Para a linhagem 870 (Figura 2E), verificou-se que a deficiência hídrica não promoveu alterações significativas no TRA, na fotossíntese, na transpiração, no teor de cera nem na massa seca da parte aérea, demonstrando assim alto nível de tolerância à deficiência hídrica.

Comparando os genótipos com disponibilidade hídrica, percebeu-se que todos apresentaram TRA acima de $64 \%$, sendo a linhagem 322 a mais afetada $(64,24 \%)$ e tendo as linhagens 967 e 870 os maiores valores para o TRA, com 84,94 e $85,20 \%$, respectivamente. Entre os genótipos sob deficiência hídrica, observou-se que a cultivar IAC Tatu-ST foi a mais afetada, com 22,82\%, seguida da linhagem 322 e das cultivares IAC 505 e IAC 503, com 34,81, 39,17 e 45,62\% (Tabela 3).

Para a fotossíntese das plantas sem deficiência hídrica, as cultivares IAC 503 e IAC 505 tiveram meIhor desempenho. As linhagens 870, 599 e 573 e as cultivares IAC Tatu-ST e IAC OL4 foram as mais

Tabela 2 - Resumo da análise de variância para o teor relativo de água (TRA), fotossíntese (A), transpiração (E), teores de cera epicuticular (TC) e massa seca da parte aérea (MSPA) de genótipos de amendoim submetidos a condições hídricas.

\begin{tabular}{|c|c|c|c|c|c|}
\hline & TRA & A & $E$ & TC \\
\hline$F(H)$ & $12,68^{*}$ & $14,50^{*}$ & $55,51^{*}$ & $37,95^{*}$ & $21,68^{*}$ \\
\hline$F(G)$ & $76,99^{*}$ & $319,55^{*}$ & $381,64^{*}$ & $5,03^{*}$ & $59^{*}$ \\
\hline$F(H x G)$ & $6,87^{*}$ & $10,29 *$ & $34,98^{*}$ & $7,78^{*}$ \\
\hline CV (\%) & 12,16 & 2,09 & 19,57 & 27,38 & 11,39 \\
\hline
\end{tabular}

F: fator de significância; H: condição hídrica; G: genótipos; CV, coeficiente de variância; *1\% de probabilidade. 
A

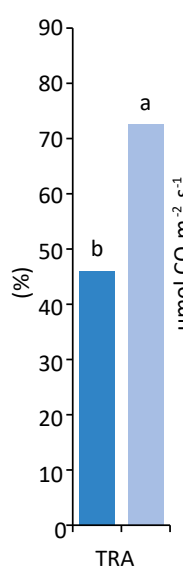

C

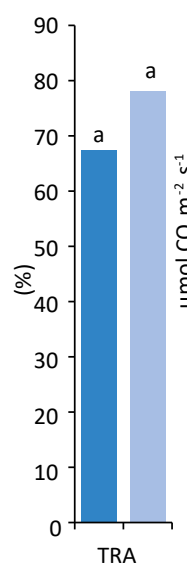

E
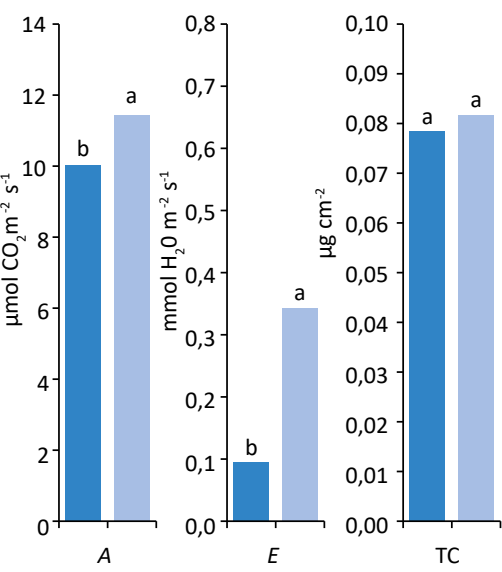

CV. IAC OL3

Cv. Runner IAC 886

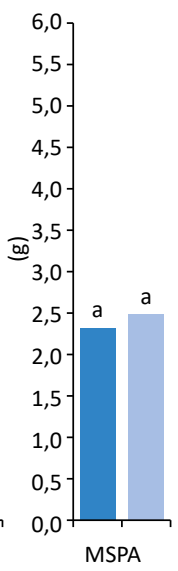

MSPA
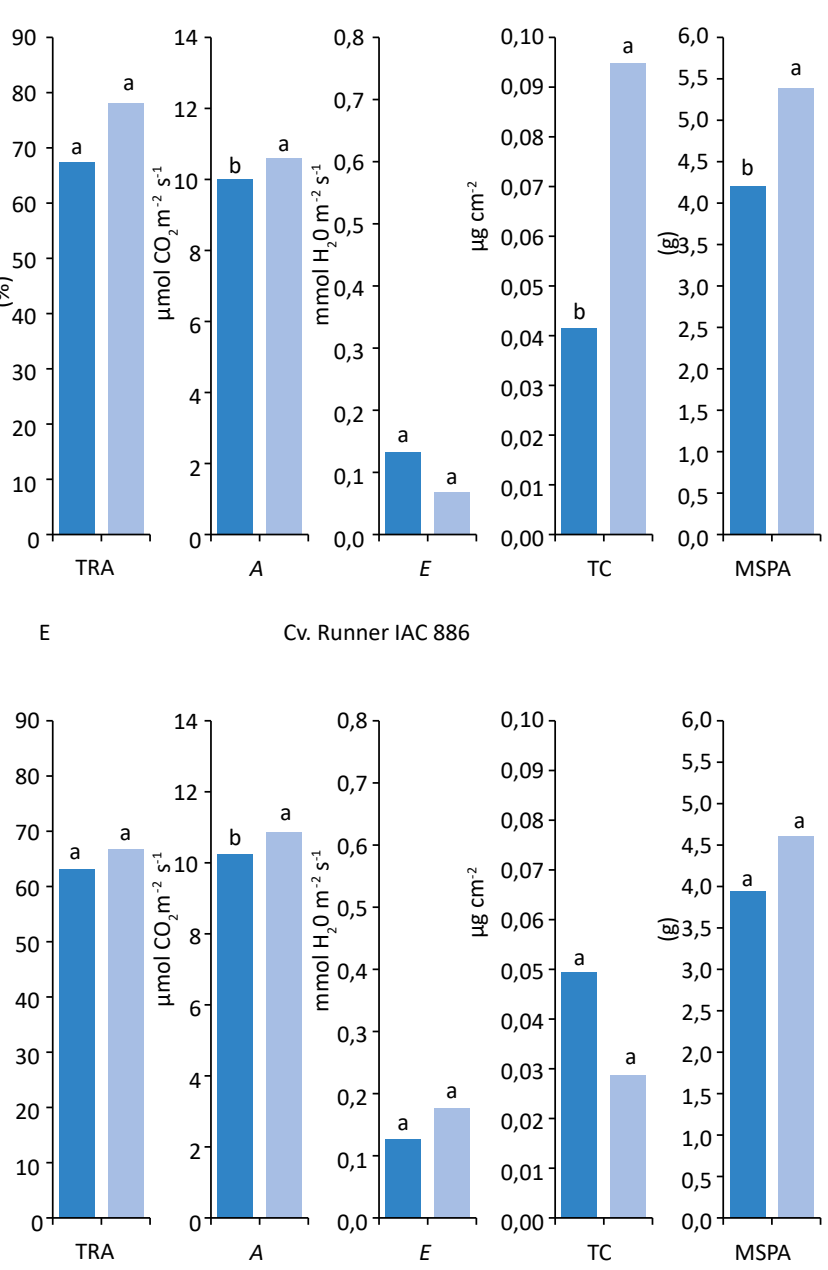

B
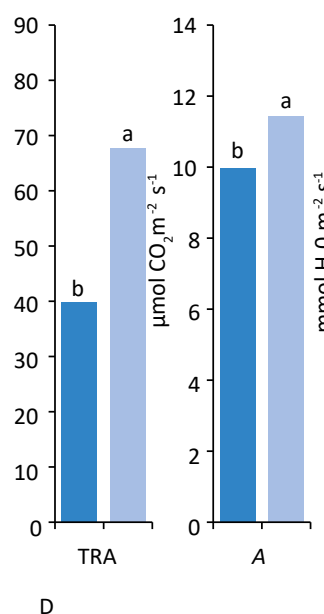

Cv. IAC 505
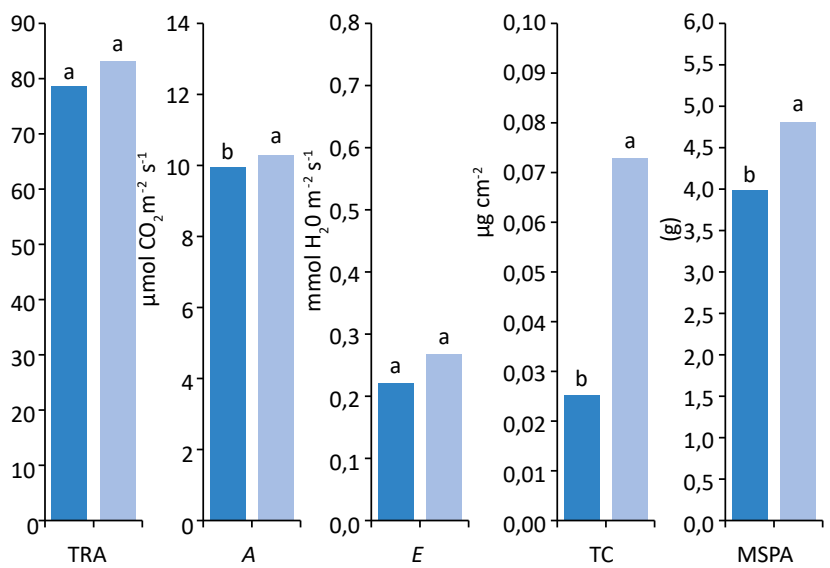

$\mathrm{F}$

CV. IAC Tatu-ST
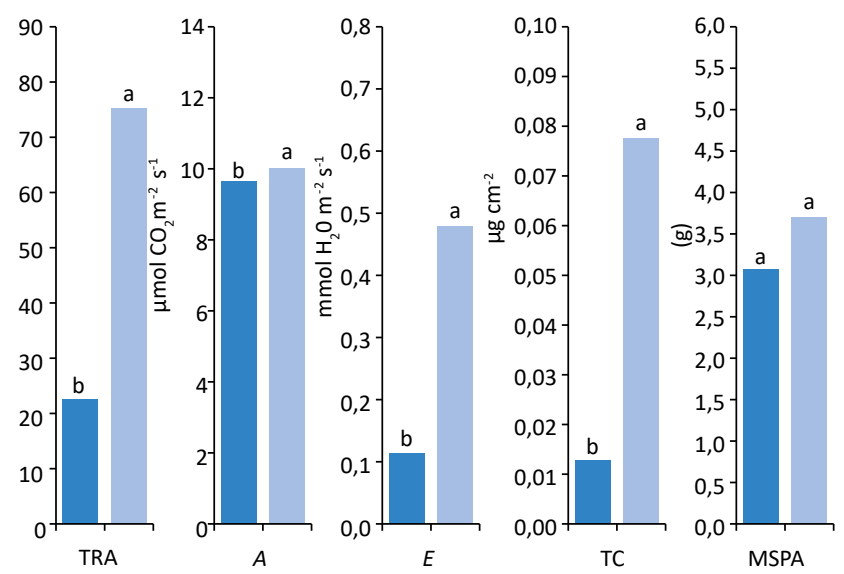

Sem estresse

TRA: teor relativo de água; $A$ : fotossíntese; $E$ : transpiração; TC: teor de cera epicuticular; MSPA: massa seca da parte aérea.

Figura 1 - Comportamento fisiológico de seis cultivares de amendoim submetidos à deficiência hídrica. 


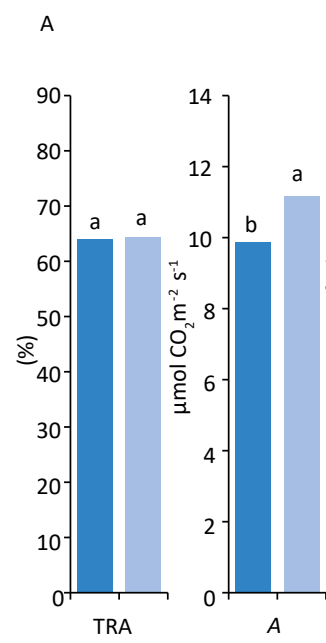

L. 322
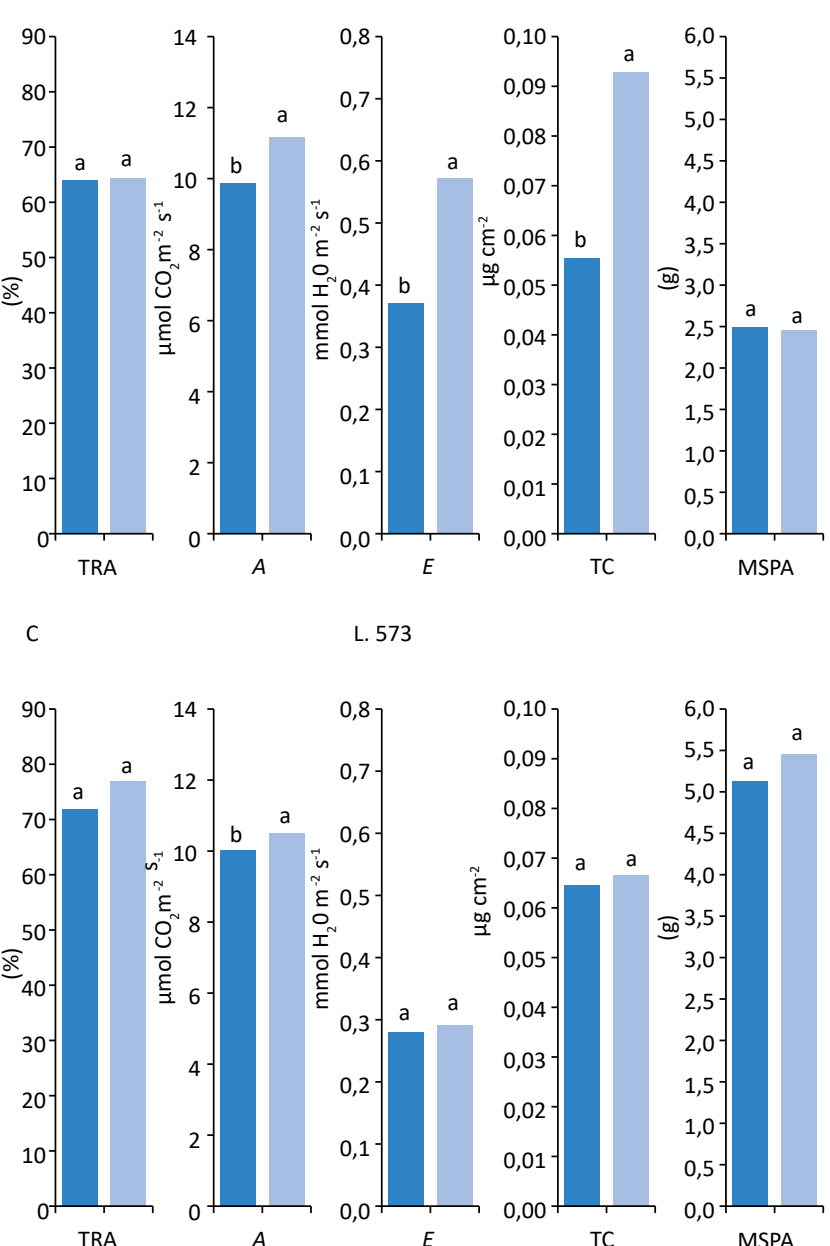

L. 573

$$
\text { E }
$$
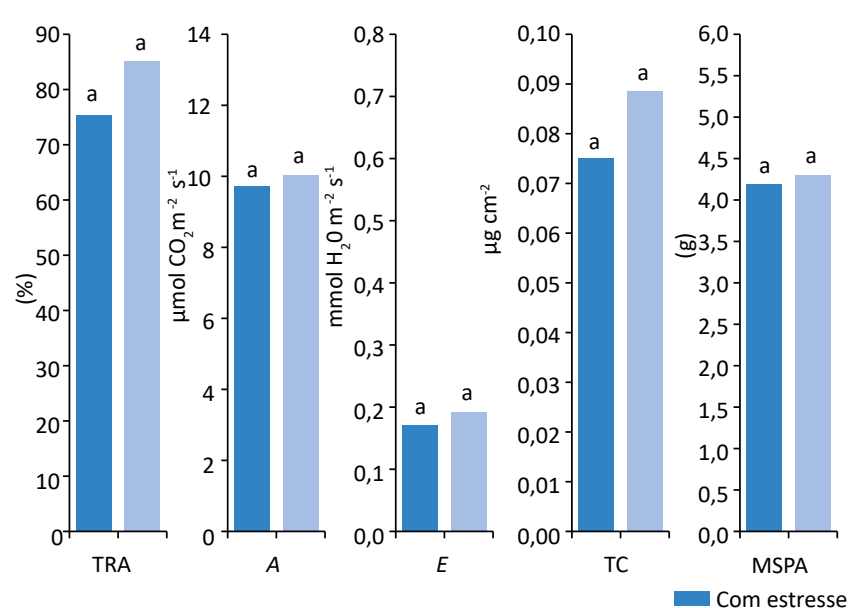

B

L. 506
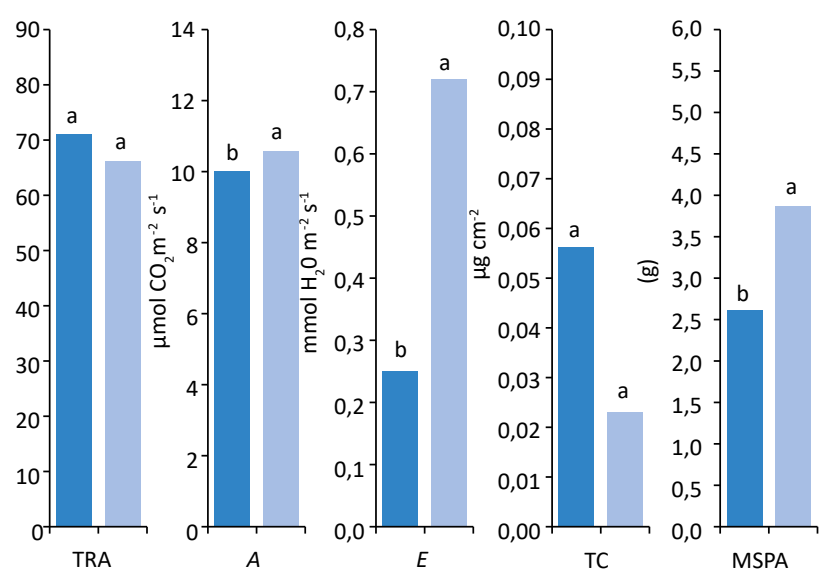

D

L. 599
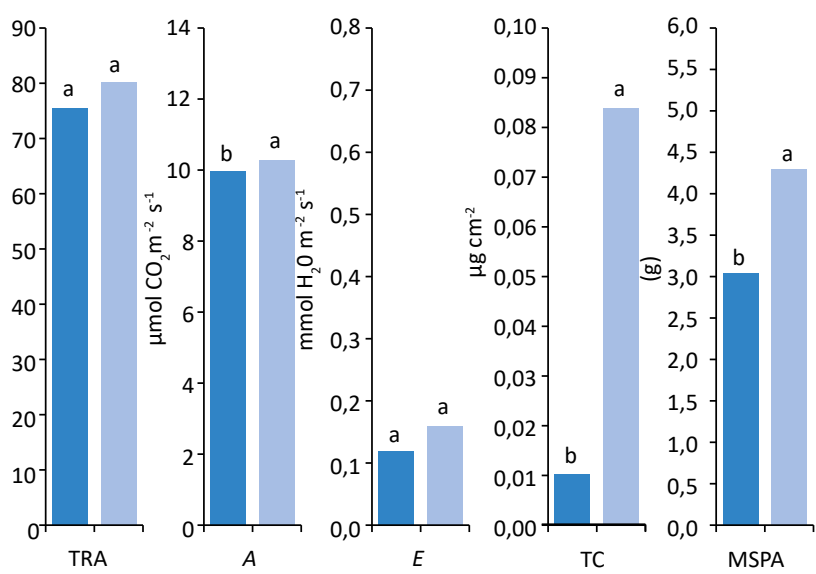

L. 967
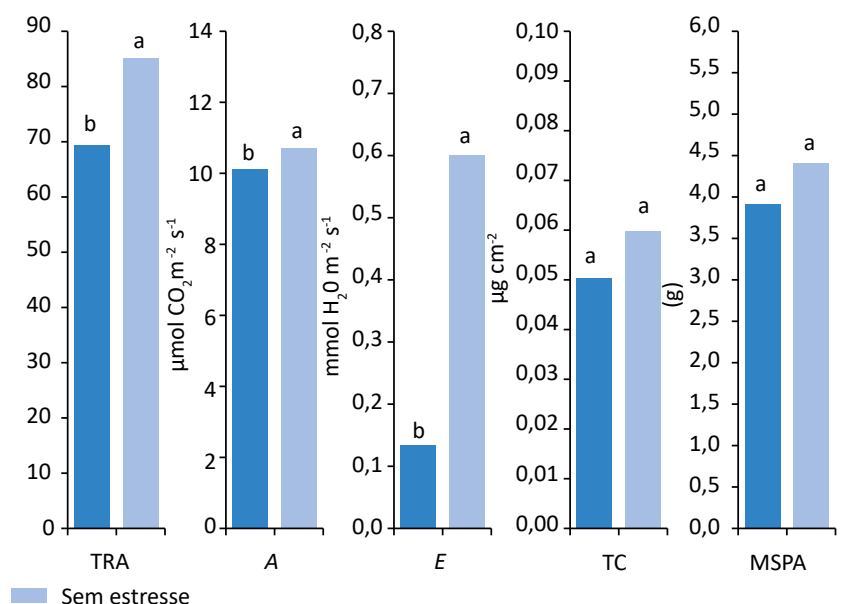

TRA: teor relativo de água; $A$ : fotossíntese; $E$ : transpiração; TC: teor de cera epicuticular; MSPA: massa seca da parte aérea.

Figura 2 - Comportamento fisiológico de seis linhagens de amendoim submetidos à deficiência hídrica. 
afetadas, exibindo menor taxa fotossintética, com 10,$05 ; 10,27 ; 10,50 ; 10,11$ e $10,29 \mu \mathrm{mol} \mathrm{CO} \mathrm{m}^{-2} \mathrm{~s}^{-1}$. Quando as plantas foram submetidas à deficiência hídrica, apesar de os valores serem inferiores quando comparados com os das plantas hidratadas, não houve diferença significativa entre os genótipos estudados.

Analisando a transpiração dos genótipos, verificou-se grande variação, e, entre aqueles sob disponibilidade hídrica, constatou-se que a linhagem 506 foi a que apresentou maior transpiração $\left(0,72 \mu \mathrm{mol} \mathrm{H} \mathrm{H}_{2} \mathrm{~m} \mathrm{~m}^{-2} \mathrm{~s}^{-1}\right)$, enquanto as cultivares IAC OL3, IAC Runner 886 e a linhagem 870 tiveram menor perda de água para o ambiente, com 0,07, 0,17 e 0,19 $\mu \mathrm{mol} \mathrm{H}_{2} 0 \mathrm{~m}^{-2} \mathrm{~s}^{-1}$, demonstrando maior tolerância entre os genótipos. Sob condição limitante de água, todos os genótipos apresentaram reduções na transpiração, e a cultivar IAC 503 foi a que mais tolerou a deficiência hídrica.

Para o teor de cera epicuticular, entre os genótipos sob disponibilidade hídrica, as cultivares IAC 503 e IAC OL3 e as linhagens 322, 599 e 870 tiveram os maiores teores quando comparadas com a cultivar Runner IAC

Tabela 3 - Efeito da deficiência hídrica sobre características fisiológicas de 12 genótipos de amendoim aos 29 dias após a emergência.

\begin{tabular}{|c|c|c|c|c|c|c|c|c|c|c|}
\hline & \multicolumn{2}{|c|}{ TRA } & \multicolumn{2}{|c|}{$A$} & \multicolumn{2}{|c|}{$E$} & \multicolumn{2}{|c|}{ TC } & \multicolumn{2}{|c|}{ MSPA } \\
\hline Genótipos & $\mathrm{CDH}$ & SDH & $\mathrm{CDH}$ & SDH & $\mathrm{CDH}$ & SDH & $\mathrm{CDH}$ & SDH & $\mathrm{CDH}$ & SDH \\
\hline cV. IAC 503 & $45,62 \mathrm{~cd}$ & $72,38 a b$ & 10,05 a & 11,43 a & $0,09 d$ & $0,34 \mathrm{~d}$ & $\begin{array}{c}0,0584 \\
a b\end{array}$ & $\begin{array}{c}0,0817 \\
a b\end{array}$ & $2,31 d$ & $2,48 \mathrm{c}$ \\
\hline CV. IAC 505 & $39,17 \mathrm{~cd}$ & $67,27 a b$ & 9,85 a & $11,34 \mathrm{a}$ & $0,11 \mathrm{~cd}$ & $0,53 \mathrm{bc}$ & $\begin{array}{c}0,0294 \\
\text { bcd }\end{array}$ & $\begin{array}{c}0,0606 \\
\text { abcd }\end{array}$ & $3,99 a b$ & $4,04 \mathrm{~b}$ \\
\hline cV. IAC 886 & $\begin{array}{c}62,62 \\
a b c\end{array}$ & $66,58 a b$ & $10,14 a$ & 10,77 bc & $0,12 \mathrm{~cd}$ & $0,17 \mathrm{fg}$ & $\begin{array}{c}0,0485 \\
\text { abcd }\end{array}$ & $\begin{array}{c}0,0283 \\
c d\end{array}$ & $3,89 a b$ & $4,56 a b$ \\
\hline cV. IAC OL3 & $67,42 a b$ & $77,95 a b$ & $10,01 \mathrm{a}$ & $\begin{array}{l}10,59 \\
\text { cde }\end{array}$ & $0,13 \mathrm{~cd}$ & $0,07 \mathrm{~g}$ & $\begin{array}{c}0,0412 \\
\text { abcd }\end{array}$ & $0,0948 a$ & $4,22 a b$ & 5,36 a \\
\hline CV. IAC OL4 & 78,31 a & $83,01 \mathrm{ab}$ & 9,93 a & $\begin{array}{c}10,29 \\
\text { cdef }\end{array}$ & 0,22 bc & 0,27 def & $\begin{array}{c}0,0250 \\
\text { bcd }\end{array}$ & $\begin{array}{c}0,0741 \\
\text { ab }\end{array}$ & $3,96 a b$ & $4,80 a b$ \\
\hline cv. IAC Tatu-ST & $22,82 \mathrm{~d}$ & $75,65 a b$ & 9,69 a & 10,11 ef & $0,11 \mathrm{~cd}$ & $0,48 c$ & $\begin{array}{c}0,0119 \\
\text { cd }\end{array}$ & $\begin{array}{c}0,0775 \\
a b\end{array}$ & $\begin{array}{l}3,10 \\
\text { abcd }\end{array}$ & $3,71 b$ \\
\hline L. 322 & $34,81 \mathrm{~cd}$ & $64,24 b$ & 9,84 a & $11,17 \mathrm{ab}$ & 0,37 a & $0,57 \mathrm{bc}$ & $\begin{array}{c}0,0535 \\
a b c\end{array}$ & $\begin{array}{c}0,0464 \\
\text { bcd }\end{array}$ & $2,49 d$ & $2,44 \mathrm{c}$ \\
\hline L. 506 & $70,78 a b$ & $65,99 a b$ & $10,04 \mathrm{a}$ & $\begin{array}{c}10,58 \\
\text { cde }\end{array}$ & $0,25 \mathrm{~b}$ & $0,72 \mathrm{a}$ & $\begin{array}{c}0,0562 \\
a b\end{array}$ & $0,0227 d$ & $2,62 \mathrm{~cd}$ & $3,88 \mathrm{~b}$ \\
\hline L. 573 & $71,64 a b$ & $76,77 a b$ & 9,99 a & $\begin{array}{l}10,50 \\
\text { cdef }\end{array}$ & $0,28 a b$ & 0,29 de & $\begin{array}{c}0,0642 \\
a b\end{array}$ & $\begin{array}{c}0,0662 \\
a b c\end{array}$ & $5,13 a$ & $5,47 a$ \\
\hline L. 599 & 75,49 a & $79,68 a b$ & 9,94 a & 10,27 def & $0,12 \mathrm{~cd}$ & 0,16 ef & $0,0103 d$ & $\begin{array}{c}0,0839 \\
a b\end{array}$ & $3,04 \mathrm{bcd}$ & $4,29 a b$ \\
\hline L. 870 & 75,38 a & 85,20 & $9,77 \mathrm{a}$ & $10,05 \mathrm{f}$ & $0,17 \mathrm{bcd}$ & 0,19 efg & 0,0751 a & 0,0885 a & $4,19 a b$ & $4,31 a b$ \\
\hline L. 967 & $68,96 a b$ & 84,94 a & 10,05 a & $10,66 \mathrm{~cd}$ & $0,13 \mathrm{~cd}$ & $0,60 \mathrm{~b}$ & $\begin{array}{c}0,0501 \\
\text { abcd }\end{array}$ & $\begin{array}{c}0,0593 \\
\text { abcd }\end{array}$ & $3,91 a b$ & $4,37 a b$ \\
\hline $\mathrm{F}$ & $16,09 * *$ & $3,42 * *$ & $1,61^{\text {ns }}$ & $19,87^{* *}$ & $55,51 * *$ & $331,64 * *$ & $5,66 * *$ & $7,16 * *$ & $8,33 * *$ & $15,91 * *$ \\
\hline C.V. (\%) & 12 & 16 & & 24 & 19, & ,57 & 24 & 41 & & 11,39 \\
\hline
\end{tabular}

Médias seguidas de mesma letra minúscula na coluna não diferem entre si pelo teste de Tukey; ${ }^{* * 1 \%}$ de probabilidade; ${ }^{\text {ns }}$ não significativo; TRA: teor relativo de água (\%); $A$, fotossíntese $\left(\mu \mathrm{mol} \mathrm{CO} \mathrm{m}^{-2} \mathrm{~s}^{-1}\right)$; $E$ : transpiração $\left(\mu \mathrm{mol} \mathrm{H}_{2} \mathrm{O} \mathrm{m}^{-2} \mathrm{~s}^{-1}\right)$; TC: teor de cera epicuticular $\left(\mu \mathrm{g} . \mathrm{cm}{ }^{-2}\right)$; MSPA,: mssa seca da parte aérea (g); $C D H$,: co deficiência hídrica; SDH,: semdeficiência hídrica; cv.,: cutivares; L.,: Inhagem; C.V.,: coeficente de variação; F: fator de significância. 
886 e com a linhagem 506. Sob deficiência hídrica, verificou-se semelhança entre todos os genótipos, com a cultivar IAC Tatu-ST e a linhagem 599 alcançando os menores teores de cera quando comparadas com as linhagens 573 e 870 .

Independentemente da condição hídrica, a linhagem 573 demonstrou maior massa seca da parte aérea quando comparada aos demais genótipos, e a cultivar IAC 503 e a linhagem 322 foram as de menor massa seca da parte aérea.

O dendrograma resultante da análise de agrupamento evidenciou, com base nos parâmetros avaliados, distinção entre os efeitos dos tratamentos com e sem deficiência hídrica, formando dois grandes grupos (Figura 3). O primeiro grupo (G1) foi composto de plantas com disponibilidade hídrica, com exceção das linhagens 870 e 573, e o segundo grupo (G2), de plantas com deficiência hídrica, com exceção do cultivar Runner IAC 886.

Em cada grande grupo (G1 e G2), destacaram-se as cultivares mais semelhantes, subdivididas em quatro subgrupos (S1, S2, S3, S4). No grupo G1, o subgrupo S1, constituído das cultivares IAC 503, IAC 505 e IAC Tatu-ST e das linhagens 322, 506 e 967, reuniu genótipos com disponibilidade hídrica (Figura 3), mas foram considerados os mais sensíveis em função dos menores valores para os teores de cera epicuticular e massa seca da parte aérea.

O subgrupo S2 (G1), constituído das cultivares IAC OL3 e IAC OL4 e das linhagens 573, 599 e 870, com disponibilidade hídrica, e das linhagens 573 e 870 com deficiência hídrica, foi semelhante entre si. Nesse subgrupo (S2), a presença das linhagens 870 e 573 em ambas as condições hídricas indicou comportamento parecido desses materiais tanto com disponibilidade de água quanto sem tal disponibilidade, revelando assim maior tolerância desses materiais genéticos à deficiência hídrica em comparação aos demais estudados.

No grupo G2, o subgrupo S3, constituído das cultivares IAC OL3, IAC OL4 e Runner IAC 886 e das linhagens 599 e 967, com deficiência hídrica, e da cultivar Runner IAC 886, com disponibilidade hídrica, foi considerado moderadamente tolerante à deficiência hídrica. A presença da cultivar Runner IAC 886 com disponibilidade hídrica no subgrupo S3 apontou similaridade dessa cultivar com os genótipos estressados desse grupo.

O subgrupo S4 (G2), constituído das cultivares IAC 503, IAC 505 e IAC Tatu-ST e das linhagens 322 e 506, com deficiência hídrica, apresentou semelhanças entre seus genótipos. Eles foram considerados os materiais mais suscetíveis ao estresse. Além disso, tiveram agrupamento similar ao observado no subgrupo S1, com exceção da linhagem 967 (Figura 3).

Além da análise de agrupamento pelo método de Ward (Figura 3), realizou-se também a ACP, visando reduzir o número de variáveis da matriz original dos dados envolvidos no modelamento feito preliminarmente. $\mathrm{Na} A C P$, como a matriz utilizada foi a de correlação, os componentes retidos foram aqueles que apresentaram os autovalores maiores que 1,0, conforme mencionado por Silveira, Vieira e Righi (2018). Diante disso, selecionaram-se dois componentes principais, com valores correspondentes a 2,1 e 1,5 (Figura 4). Segundo Barros et al. (2018), os valores dos componentes principais são baseados na variância acumulada a aproximadamente $70 \%$. No presente estudo, os dois primeiros componentes somaram $70,4 \%$ da variância dos dados originais, podendo, assim, ser utilizados para constatar semelhanças e diferenças no conjunto amostral (Figura 4).

Com base na ACP, observou-se separação entre os parâmetros teor de cera epicuticular, TRA e massa da parte aérea da fotossíntese e transpiração. Além disso, constatou-se separação entre os genótipos com deficiência hídrica dos genótipos com disponibilidade hídrica, com exceção das linhas 870 e 573, com deficiência hídrica, que se correlacionaram positivamente aos genótipos com disponibilidade hídrica, apresentando, assim, maior tolerância (Figura 5).

De modo geral, a taxa fotossintética foi menor para todos os genótipos sob deficiência hídrica, exceto para a linhagem 870, que demonstrou maior tolerância à seca. Em relação à transpiração, os genótipos Runner IAC 886, IAC OL3 e IAC OL4 e as linhagens 573, 599 e 870 não foram afetados pelo estresse hídrico. Entre os genótipos, há variação na quantidade de ceras epicuticulares sob condições hídricas. Todos os genótipos apresentaram maiores teores de ceras epicuticulares 
sob disponibilidade hídrica, exceto a linhagem 506 e a cultivar Runner IAC 886. A camada de cera na superfície foliar não atuou como um dos principais mecanismos na tolerância contra a deficiência hídrica dos genótipos de amendoim estudados. Com base no TRA, percebeu-se que todos os genótipos, com exceção das cultivares IAC 503, IAC 505 e IAC Tatu-ST e da linhagem 506, sob quatro dias de estresse, demonstraram potencial para a realização das suas atividades metabólicas normais.

\section{DISCUSSÃO}

Segundo Larcher (2006), em plantas sob deficiência hídrica ocorre inicialmente alteração nas propriedades das membranas celulares, causando a diminuição em sua turgescência. Com isso, ocorre o fechamento estomático, resultando em diminuição na transpiração das plantas de amendoim (HARO; CARREGA, 2019),

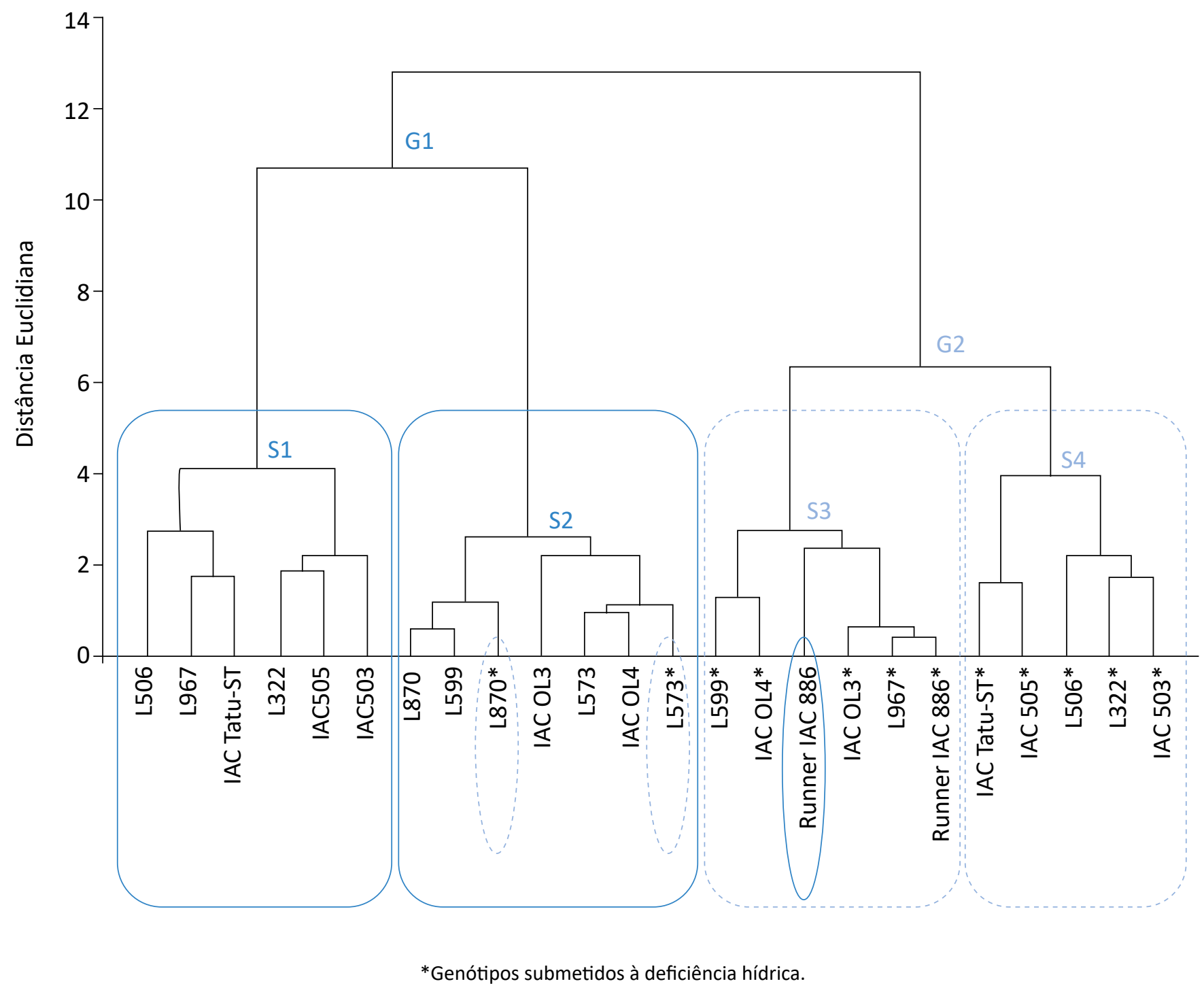

Figura 3 - Análise de agrupamento pelo método de Ward dos grupos G1 e G2, separados por subgrupos (S1-S4) para as variáveis: massa seca de parte área, fotossíntese, transpiração, teor relativo de água e teor de cera epicuticular, para os 12 genótipos em condições de disponibilidade e deficiência hídrica. 
redução da área foliar (CARREGA, 2017), menor absorção de radiação (HARO et al., 2008) e redução na taxa fotossintética das plantas (como observado em todos os genótipos sob deficiência hídrica, com exceção da linhagem 870), não somente pela menor disponibilidade de água para o processo em si, mas também pelo menor influxo de íons. Consequentemente, tem-se redução no processo de crescimento e desenvolvimento das plantas, acarretando menor produção de massa, levando à senescência prematura e induzindo à diminuição na produção das vagens (UPADHYAYA et al., 2011; PEREIRA et al., 2012; DUARTE; MELO FILHO; SANTOS, 2013; ARRUDA et al., 2015).

Resultados semelhantes foram constatados por Nogueira et al. (2006) e Nogueira e Santos (2000) ao avaliarem plantas de amendoim submetidas à deficiência hídrica. Os autores verificaram redução na taxa trans- piratória de genótipos de amendoim aos 30 DAS decorrente do déficit hídrico. A deficiência hídrica, dependendo da intensidade, prejudica as funções vitais das plantas e estimula reações de adaptação no ambiente sob condições estressantes. Segundo Graciano, Santos e Nogueira (2016), a ausência de água estimula o fechamento estomático das cultivares BR1 e BRS Havana, reduzindo a condutância estomática e a transpiração foliar, fato considerado como uma estratégia de adaptação a essa condição.

Carrega et al. (2019), estudando o efeito do estresse hídrico na germinação e no desenvolvimento radicular de genótipos de amendoim, verificaram alto nível de tolerância à deficiência hídrica para as cultivares IAC 503, Runner IAC 886, IAC OL3, IAC OL4 e IAC Tatu-ST e linhagens 322, 506, 599, 870 e 967. Pereira et al. (2010) também notaram diferenças nos TRA de genó-

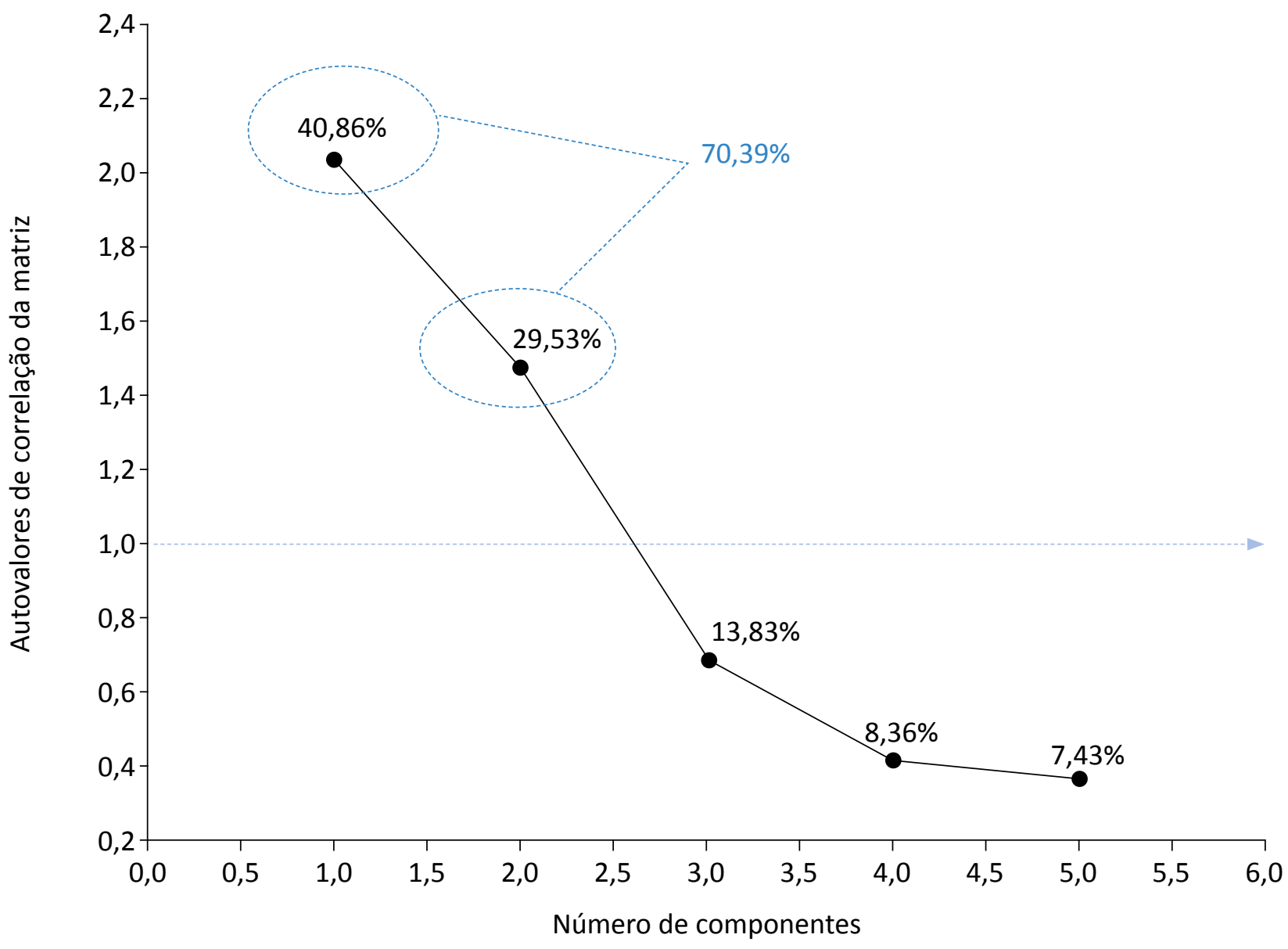

Figura 4 - Seleção dos componentes principais baseados em autovalores de correlação acima de 1,0 e variância $\approx 70 \%$. 
tipos de amendoim submetidos à deficiência hídrica. Eles observaram que os genótipos LVIPE-06, LBM e LBR apresentaram reduções nos teores de água, enquanto a cultivar BR1 exibiu maior teor de água.

Segundo alguns autores, cutículas mais espessas reduzem a transpiração cuticular, representando vantagens para as espécies sob deficiência hídrica (TIPTON; WHITE, 1995; BONDADA et al., 1996; KOTTAPALLI et al., 2009). Entretanto, no presente trabalho, observou-se menor ou igual teor de ceras em plantas de amendoim sob deficiência hídrica, à exceção da linhagem 506. Em comparação às respostas fisiológicas, a quantidade de cera não foi um dos mecanismos responsáveis pela tolerância à deficiência hídrica dos genótipos analisados, visto que os genótipos com menor quantidade de cera não apresentaram aumento na transpiração (perda de água).
Estudos com ceras epicuticulares em amendoim têm revelado resultados contraditórios, dependendo do genótipo ou da espécie (VAKHARIA, 1993; VAKHARIA et al., 1997). Samdur et al. (2003) verificaram aumento no teor de ceras quando genótipos de amendoim foram submetidos à deficiência hídrica, contudo Souza (2009) não viu diferenças estatísticas em relação à quantidade de ceras de cultivares e espécies silvestres de amendoim sob deficiência hídrica.

Oliveira, Meirelles e Salatino (2003) constataram que nem sempre o teor de ceras epicuticulares é indício de melhor eficiência contra a perda de água. Souza (2009) relatou que a tolerância à deficiência hídrica não é consequência imediata de modificações cuticulares. De acordo com ele, outros mecanismos fisiológicos, como, por exemplo, o comportamento estomático, podem responder mais

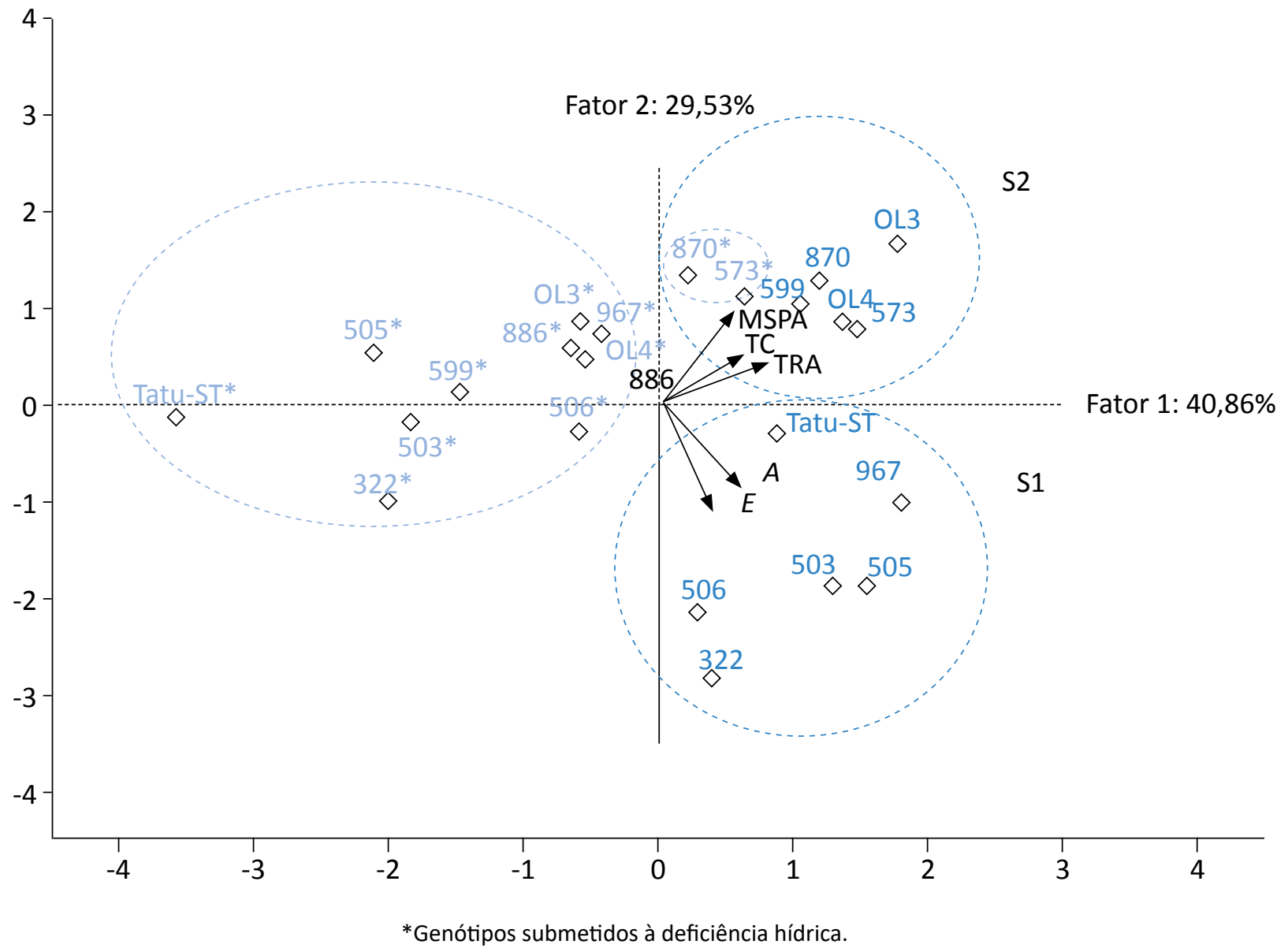

Figura 5 - Análise de componentes principais para as variáveis: massa seca da parte área (MSPA), fotossíntese (A), transpiração (E), teor relativo de água (TRA) e teor de cera epicuticular (TC), para os 12 genótipos em condições de disponibilidade e deficiência hídrica. 
diretamente à adaptação de genótipos de amendoim à restrição hídrica. Para Nogueira et al. (2006), o fechamento estomático é um dos mecanismos mais importantes, destinados a reduzir a deficiência hídrica interna, para suportar determinados períodos de seca.

Em virtude do fechamento estomático, ocorrem menor sequestro de $\mathrm{CO}_{2}$ pelas plantas, reduzindo a produção de fotoassimilados, e, consequentemente, menor capacidade de produção de fitomassa pela cultura. Arruda et al. (2015), estudando o impacto da deficiência hídrica em amendoim, constataram reduções no acúmulo de massa seca de genótipos de amendoim sob deficiência hídrica, mostrando, assim, variabilidade genotípica entre as plantas de A. hypogaea. Graciano, Santos e Nogueira (2016), avaliando duas cultivares de amendoim, também verificaram menor produção de biomassa seca total de plantas submetidas a déficit hídrico no solo.

Além de condições de estresse, outros fatores, como a idade da planta, podem influenciar na deposição de cera epicuticular na superfície foliar. Dessa forma, uma possível explicação para a menor quantidade de cera sob deficiência hídrica é o fato de as plantas nessa condição apresentarem restrição do desenvolvimento em comparação a plantas sob disponibilidade de água. Além disso, plantas de amendoim exibem hábito de crescimento indeterminado. Ou seja, as plantas mantêm emissões de flores e ginóforos durante todo o ciclo de cultivo. No entanto, entre os 35 e os 45 DAS, ocorre o maior pico de florescimento. Nesse momento, a restrição de água no solo afeta o desenvolvimento das estruturas vegetativas das plantas, podendo causar aborto de flores e, por conseguinte, inibição na produção de ginóforos, vagens e sementes.

O grau de tolerância à seca pode variar entre espécies e entre genótipos de uma mesma espécie, sendo a tolerância dependente da duração e da intensidade do estresse. Diante da escassez de informações, as respostas obtidas no presente estudo são de fundamental importância para o programa de melhoramento de amendoim no Brasil.

\section{CONCLUSÕES}

Sob fatores ambientais, como a deficiência hídrica durante a fase de florescimento do amendoim, as linhagens 573 e 870 são altamente tolerantes à deficiência hídrica, IAC OL3, IAC
OL4 e Runner IAC 886 e as linhagens 599 e 967 são moderadamente tolerantes, e IAC 503, IAC 505 e IAC Tatu-ST e as linhagens 322 e 506 são mais sensíveis à deficiência hídrica.

\section{AGRADECIMENTOS}

Os autores prestam seus agradecimentos ao Conselho Nacional de Desenvolvimento Científico e Tecnológico (CNPq), a concessão de bolsa de estudo para o primeiro (processo no 142.462/2013-

6) e último (processo no 306.749/2017-3) autores.

\section{REFERÊNCIAS}

ARRUDA, I.M.; MODA-CIRINO, V.; BURATTO, J.S.; FERREIRA, J.M. Crescimento e produtividade de cultivares e linhagens de amendoim submetidas a déficit hídrico. Pesquisa Agropecuária Tropical, v. 45, n. 2, p. 146-154, 2015. https://doi. org/10.1590/1983-40632015v4529652

BARBOSA, J.C.; MALDONADO JÚNIOR, W. Experimentação agronômica \& agroestat-sistema para análises estatísticas de ensaios agronômicos. Jaboticabal: Multipress, 2015. 
BARROS, T.D.F.S.; RIOS, E.S.C.; MAIA, L.D.M.; DANTAS, R.L.; DE MELO SILVA, S. Qualidade de frutos de cultivares de mamão comercializados em supermercados de Campina Grande-PB. Agropecuária Técnica, v. 39, n. 2, p. 129-142, 2018. https://doi.org/10.25066/agrotec.v39i2.38109

BONDADA, B.R.; OOSTERHUIS, D.M.; MURPHY, J.B.; KIM, K.S. Effect of water stress on the epicuticular wax composition and ultrastructure of cotton (Gossypium hirsutum L.) leaf, bract, and boll. Environmental and Experimental Botany, v. 36, n. 1, p. 61-69, 1996. https://doi.org/10.1016/0098-8472(96)00128-1

BUSCHHAUS, C.; HERZ, H.; JETTER, R. Chemical composition of the epicuticular and intracuticular wax layers on adaxial sides of Rosa canina leaves. Annals of botany, v. 100, n. 7, p. 1557-1564, 2007. https://doi.org/10.1093/aob/mcm255

CARREGA, W.C. Deficiência hídrica em genótipos de amendoim. Tese (Doutorado) - Universidade Estadual Paulista "Júlio de Mesquita Filho", Jaboticabal, 2017.

CARREGA, W.C.; MARTINS, P.F.R.B.; BACHA, A.L.; CESARIN, A.E.; OLIVEIRA, T.S.; GODOY, I.J.; ALVES, P.L.C.A. Physiological response of seeds of peanut genotypes to water deficiency. Bioscience Journal, v. 35, n. 3, p. 741-751, 2019. https:// doi.org/10.14393/BJ-v35n3a2019-41876

DUARTE, E.A.; MELO FILHO, P.D.A.; SANTOS, R.C. Características agronômicas e índice de colheita de diferentes genótipos de amendoim submetidos a estresse hídrico. Revista Brasileira de Engenharia Agrícola e Ambiental, v. 17, n. 8, p. 843-847, 2013. http://dx.doi.org/10.1590/S1415-43662013000800007

EVANS, J.R.; SANTIAGO, L.S. PrometheusWiki gold leaf protocol: gas exchange using LI-COR 6400. Functional Plant Biology, v. 41, n. 3, p. 223-226, 2014. https://doi.org/10.1071/FP10900

GIRDTHAI, T.; JOGLOY, S.; VORASOOT, N.;AKKASAENG, C.; WONGKAEW, S.; HOLBROOK, C.C.; PATANOTHAI, A. Associations between physiological traits for drought tolerance and aflatoxin contamination in peanut genotypes under terminal drought. Plant Breeding, v. 129, n. 6, p. 693-699, 2010. https://doi.org/10.1111/j.1439-0523.2009.01738.x

GRACIANO, E.S.A.; SANTOS, H.R.B.; NOGUEIRA, R.J.M.C. Trocas gasosas, eficiência fotoquímica e pigmentos fotossintéticos de cultivares de amendoim sob deficiência hídrica no solo. Brazilian Journal of Applied Technology for Agricultural Science, v. 9, n. 1, p. 27-36, 2016.

GUHLING, O.; KINZLER, C.; DREYER, M.; BRINGMANN, G.; JETTER, R. Surface composition of myrmecophilic plants: cuticular wax and glandular trichomes on leaves of Macaranga tanarius. Journal of Chemical Ecology, v. 31, p. 23232341, 2005. https://doi.org/10.1007/s10886-005-7104-1

HARO, R.J.; CARREGA, W.C. Efeitos do estresse hídrico na cultura do amendoim. In: SILVA, R.P.; SANTOS, A.F.; CARREGA, W.C. (orgs.). Avanços na produção de amendoim. Jaboticabal: Funep, 2019. p. 55-66.

HARO, R.J.; DARDANELLI, J.L.; OTEGUI, M.E.; COLLINO, D.J. Seed yield determination of peanut crops under water deficit: Soil strength effects on pod set, the source-sink ratio and radiation use efficiency. Field Crops Research, v. 109, n. 1-3, p. 24-33, 2008. https://doi.org/10.1016/j.fcr.2008.06.006

KAMBIRANDA, D.M.; VASANTHAIAH, H.K.; KATAM, R.; ANANGA, R.K.A.; BASHA, S.M.; NAIK, K. Impact of drought stress on peanut (Arachis hypogaea L.) productivity and food safety. In Plants and environment. IntechOpen, p. 249-272, 2011. https://doi.org/10.5772/27917

KOTTAPALLI, K.R.; RAKWAL, R.; SHIBATO, J.; BUROW, G.; TISSUE, D.; BURKE, J.; PUPPALA, N.; BUROW, M.; PAYTON, P. Physiology and proteomics of the water-deficit stress response in three contrasting peanut genotypes. Plant, Cell \& Environment, v. 32, n. 4, p. 380-407, 2009. https://doi.org/10.1111/j.1365-3040.2009.01933.x

LARCHER, W. Ecofisiologia Vegetal. 3. ed. São Carlos: RiMa, 2006. 532 p. 
NATIONAL AERONAUTICS AND SPACE ADMINISTRATION (NASA). Global climate change. Vital Signs of the Planet. California Institute of Technology, 2019. Disponível em: <https://climate.nasa.gov/vital-signs/global-temperature/>. Acesso em: 28 out. 2019.

NOGUEIRA, R.J.M.C.; MELO FILHO, P.D.A.; CARVALHO, R.; SANTOS, R.C. Comportamento estomático e potencial da água da folha em amendoim cv. BRS 151 L7 submetido a estresse hídrico. Revista Brasileira de Oleaginosas e Fibrosas, v. 10, n. 1-2, p. 985-991, 2006.

NOGUEIRA, R.J.M.C.; SANTOS, R.D. Alterações fisiológicas no amendoim submetido ao estresse hídrico. Revista Brasileira de Engenharia Agrícola e Ambiental, v. 4, n. 1, p. 41-45, 2000. http://dx.doi.org/10.1590/S1415-43662000000100008

OLIVEIRA, A.F.; MEIRELLES, S.T.; SALATINO, A. Epicuticular waxes from caatinga and cerrado species and their efficiency against water loss. Anais da Academia Brasileira de Ciências, v. 75, n. 4, p. 431-439, 2003. https://doi.org/10.1590/ S0001-37652003000400003

PEREIRA, J.D.L.; ALBUQUERQUE, M.B.; NOGUEIRA, R.J.M.C.; SANTOS, R.C.; MELO FILHO, P.D.A. Relações hídricas e ajustamento osmótico de genótipos de amendoim submetidos ao déficit hídrico. In: CONGRESSO BRASILEIRO DE MAMONA, 4.; SIMPÓSIO INTERNACIONAL DE OLEAGINOSAS ENERGÉTICAS, 2010. João Pessoa. Anais... Campina Grande: Embrapa Algodão, 2010.

PEREIRA, J.W.; MELO FILHO, P.A.; ALBUQUERQUE, M.B.; NOGUEIRA, R.M.; SANTOS, R.C. Mudanças bioquímicas em genótipos de amendoim submetidos a déficit hídrico moderado. Revista Ciência Agronômica, v. 43, n. 4, p. 766-773, 2012. http://dx.doi.org/10.1590/S1806-66902012000400019

POLANIA, J.; RAO, I.M.; CAJIAO, C.; GRAJALES, M.; RIVERA, M.; VELASQUEZ, F.; RAATZ, B.; BEEBE, S.E. Shoot and root traits contribute to drought resistance in recombinant inbred lines of MD 23-24× SEA 5 of common bean. Frontiers in Plant Science, v. 8, p. 296, 2017. https://doi.org/10.3389/fpls.2017.00296

RODRIGUES, L.G.D.S.M.; RODRIGUES, F.M.; OLIVEIRA, E.M.; VIERA, V.B.; ARÉVALO, A.M.; VIROLI, S.L.M. Peanut (Arachis sp.) as a source in the Brazilian energy matrix. Journal of Bioenergy and Food Science, v. 3, n. 3, p. 178-190, 2016. https://doi.org/10.18067/jbfs.v3i3.80

SAMDUR, M.Y.; MANIVEL, P.; JAIN, V.K.; CHIKANI, B.M.; GOR, H.K.; DESAI, S.; MISRA, J.B. Genotypic differences and water-deficit induced enhancement in epicuticular wax load in peanut. Crop Science, v. 43, n. 4, p. 1294-1299, 2003. https://doi.org/10.2135/cropsci2003.1294

SHEN, Y.; ZHIGUO, E.; ZHANG, X., LIU, Y.; CHEN, Z. Screening and transcriptome analysis of water deficiency tolerant germplasms in peanut (Arachis hypogaea). Acta Physiologiae Plantarum, v. 37, p. 103, 2015. https://doi.org/10.1007/ s11738-015-1840-9

SILVA FERNANDES, A.M.; BAKER, E.A.; MARTIN, J.T. Studies on plant cuticle: VI. The isolation and fractionation of cuticular waxes. Annals of Applied Biology, v. 53, n. 1, p. 43-58, 1964. https://doi.org/10.1111/j.1744-7348.1964.tb03779.x

SILVEIRA, V.G.D.; VIEIRA, K.M.; RIGHI, M.B. Medindo liquidez através da análise fatorial de séries temporais. Revista Brasileira de Finanças, v. 16, n. 1, p. 157-177, 2018.

SONGSRI, P.; JOGLOY, S.; VORASOOT, N.; AKKASAENG, C.; PATANOTHAI, A.; HOLBROOK, C.C. Root distribution of droughtresistant peanut genotypes in response to drought. Journal of Agronomy and Crop Science, v. 194, n. 2, p. 92-103, 2008. https://doi.org/10.1111/j.1439-037X.2008.00296.x

SOUZA, R.J.C. Ceras epicuticulares de genótipos de Arachis hypogaea L.: composição e efeito do estresse hídrico. Dissertação (Mestrado) - Universidade Federal de Pernambuco, Recife, 2009. 
STATISTICA. Statistica software package (version 13.1). Tulsa: StatSoft Inc., 2016. Disponível em: <www.statsoft.com>. Acesso em: 29 maio 2019.

TAIZ, L.; ZEIGER, E.; MØLLER, I.M.; MURPHY, A. Fisiologia vegetal. 6. ed. Porto Alegre: Artmed, 2017.

THANGTHONG, N.; JOGLOY, S.; JONGRUNGKLANG, N.; KVIEN, C.K.; PENSUK, V.; KESMALA, T.; VORASOOT, N. Root distribution patterns of peanut genotypes with different drought resistance levels under early-season drought stress. Journal of Agronomy and Crop Science, v. 204, n. 2, p. 111-122, 2018. https://doi.org/10.1111/jac.12249

TIPTON, J.L.; WHITE, M. Differences in leaf cuticle structure and efficacy among eastern redbud and Mexican redbud phenotypes. Journal of the American Society for Horticultural Science, v. 120, n. 1, p. 59-64, 1995. https://doi. org/10.21273/JASHS.120.1.59

UPADHYAYA, H.D.; SHARMA, S.; SINGH, S.; SINGH, M. Inheritance of drought resistance related traits in two crosses of groundnut (Arachis hypogaea L.). Euphytica, v. 177, p. 55-66, 2011. https://doi.org/10.1007/s10681-010-0256-2

UNITED STATES DEPARTMENT OF AGRICULTURE (USDA). Foreign Agricultural Service World Agricultural Production. Circular Series. USDA. Disponível em: <https://apps.fas.usda.gov/psdonline/circulars/production.pdf>. Acesso em: 29 maio 2019.

VAKHARIA, D.N. Changes in cuticular wax content in leaves of two groundnut cultivars during and relief of drought. Plant Physiology \& Biochemistry, v. 20, n. 1, p. 96-98, 1993.

VAKHARIA, D.; KANDOLIYA, U.; PATEL, N.; PARAMESWARAN, M. Effect of Drought on Leaf Metabolites Relationship with Pod Yield in Groundnut. Plant Physiology and Biochemistry-New Delhi, v. 24, n. 1, p. 102-105, 1997.

WEATHERLEY, P. Studies in the water relations of the cotton plant. New Phytologist, v. 49, n. 1, p. 81-97, 1950. 